\title{
miR-296-3p promotes the proliferation of glioblastoma cells by targeting ICAT
}

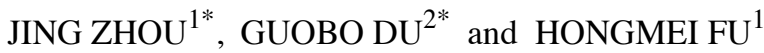 \\ Departments of ${ }^{1}$ Neurology and ${ }^{2}$ Oncology, Affiliated Hospital of North Sichuan Medical College, \\ Nanchong, Sichuan 637000, P.R. China
}

Received March 19, 2019; Accepted November 4, 2019

DOI: $10.3892 / \mathrm{mmr} .2020 .11011$

\begin{abstract}
MicroRNAs (miRNA/miRs) serve an important function in the regulation of gene expression, and have been indicated to mediate a number of cellular biological processes, including cell proliferation, the cell cycle, cell apoptosis and cell differentiation. The altered expression of miRNAs has been revealed to result in a variety of human diseases, including glioblastoma multiforme (GBM). The present study indicated an increase in miR-296-3p in glioma tumor types compared with normal brain, particularly in the samples from patients with high grade GBM. Antagonizing miR-296-3p was demonstrated to induce cell growth arrest and cell cycle redistribution in U251 cells. The miR-296-3p antagonist altered the expression of a number of key genes that are involved in cell cycle control, including cyclin D1 and p21. Additionally, the decrease of miR-296-3p increased inhibitor of $\beta$-catenin and T cell factor (ICAT) expression, and increased miR-296-3p-inhibited ICAT expression in U251 cells. Bioinformatics analysis indicated that ICAT is a target gene of miR-296-3p, which was further validated using a dual-luciferase reporter assay. Through the regulation of ICAT, the miR-296-3p antagonist decreased $\beta$-catenin protein expression and increased the expression of its target genes. Silencing ICAT was indicated to reverse the miR-296-3p downregulation-induced inactivation of Wnt signaling and cell growth arrest in glioma cells. The present study also indicated a negative correlation between ICAT mRNA levels and miR-296-3p levels in glioma tumor types. In conclusion, the present study identified an oncogenic function of miR-296-3p in glioblastoma via the direct regulation of ICAT.
\end{abstract}

Correspondence to: Dr Hongmei Fu, Department of Neurology, Affiliated Hospital of North Sichuan Medical College, 63 Wenhua Road, Nanchong, Sichuan 637000, P.R. China

E-mail: fuhongmeinsmc@163.com

*Contributed equally

Key words: microRNA-296-3p, inhibitor of $\beta$-catenin and $\mathrm{T}$ cell factor, glioblastoma, cell proliferation

\section{Introduction}

Glioma is the most common brain tumor type in humans, results in a high mortality rate and is divided into either a low grade (I and II) or high grade (II and IV) type, based on its histological features (1). Glioblastoma multiforme (GBM) is classified as a grade IV glioma according to the World Health Organization (WHO) grading system (2). Despite advancement in treatment of GBM, the majority of patients continue to succumb to the disease, which exhibits an overall survival rate of $<3$ years (3). Following surgery, chemotherapy, including DNA alkylating antineoplastic drug temozolomide (TMZ) chemotherapy, is used as the first-line treatment for patients with GBM and successfully improves overall survival time (4). However, acquired de novo resistance limits the efficacy of TMZ for patients with GBM $(5,6)$. The lack of knowledge regarding the initiation and development of GBM results in difficulty in treating patients with GBM. Therefore, an investigation of the molecular mechanism regulating GBM is urgently required.

MicroRNAs (miRNAs/miRs) are small, non-coding, single stranded RNA molecules that are ubiquitously expressed in human cells (7). miRNAs function as negative regulators of gene expression through binding to the complementary sites on the 3'-untranslated region (UTR) of target mRNAs, and decrease target gene expression via the degradation of mRNA or the inhibition of translation (8). The expression of miRNA is controlled by DNA histone modification and other epigenetic factors, and miRNAs serve an important function in a number of biological processes, including cell differentiation, cell proliferation, the cell cycle and cell motility (9-11). The initiation and development of human cancer is frequently accompanied by miRNA deregulation $(12,13)$. In GBM, accumulating evidence has demonstrated that the aberrant expression of miRNAs contributes to cancer progression $(12,14)$. The analysis of gene expression and the matched miRNA profile in patients with GBM has revealed a RNA-RNA interaction network that regulates GBM cell proliferation (14). miR-296 expression has been revealed to be increased in the primary tumor endothelial cells compared with normal brain endothelial cells (15). Furthermore, the expression of miR-296 has been indicated to be associated with cell invasion and the multi-drug resistance of glioma cells $(16,17)$. Further investigation is necessary to determine the complexity of the miRNA network in GBM. 
Inhibitor of $\beta$-catenin and $\mathrm{T}$ cell factor (TCF) (ICAT) is a well-characterized negative regulator of Wnt signaling activity, which functions by blocking the binding of TCF to $\beta$-catenin (18). ICAT is reported to be deregulated in a number of human tumor types, while its function in carcinogenesis remains yet to be determined $(19,20)$. In hepatocellular carcinoma, ICAT promotes the epithelial-to-mesenchymal transition, and is targeted and inhibited by miR-424-5p (21). In GBM, ICAT is downregulated and has been indicated to inhibit cell proliferation, migration and invasion, and induce cell apoptosis in GBM cells (22). ICAT expression is regulated by miRNAs in a number of different cancer types, including hepatocellular carcinoma and breast cancer $(21,23)$. The mechanisms by which ICAT is regulated by miRNAs has, to the best of our knowledge, not yet been determined in GBM.

\section{Materials and methods}

Patients. Glioma tissues and normal brain tissues were collected from the Affiliated Hospital of North Sichuan Medical College (Sichuan, China) between June 2014 and July 2018. GBM tissues from patients with WHO grade II, III and IV tumor types were obtained during standard surgery, and 10 patients were included for each grade. The 10 normal brain tissues were obtained during surgery in patients with intractable epilepsy. All participants provided written informed consent prior to tissue sampling. The present study was ethically approved and conducted under the supervision of the Ethics Committee of North Sichuan Medical College (approval no. NSREC20140622H). Patients were enrolled in the study if their diagnosis was histologically confirmed by two neuropathologists based on the 2007 WHO classification guidelines (24).

Cell lines. 293 cells and human GBM cell lines U251 and U138MG were purchased from the Type Culture Collection of the Chinese Academy of Sciences (Shanghai, China). Cell lines were maintained in Dulbecco's modified Eagle's medium (Gibco; Thermo Fisher Scientific, Inc., Waltham, MA, USA) containing $10 \%$ fetal bovine serum (Gibco; Thermo Fisher Scientific, Inc.) and 1\% penicillin/streptomycin (Invitrogen; Thermo Fisher Scientific, Inc.) and incubated at $37^{\circ} \mathrm{C}$ in a humidified incubator with $5 \% \mathrm{CO}_{2}$.

miR-296-3p mimics and miR-296-3p antagonist transfection. miR-negative control (NC) mimics (5'-UUCUCCGAACGU GUCACGUTT-3'), miR-296-3p mimics (5'-AGGGCCCCC CCUCAAUCCUGU-3'), miR-NC antagonist (5'-CAGUAC UUUUGUGUAGUACAA-3') and miR-296-3p antagonist (5'-ACAGGAUUGAGGGGGGGCCCU-3') were purchased from Guangzhou RiboBio Co., Ltd. (Guangzhou, China). For miR-296-3p antagonization or miR-296-3p overexpression, $200 \mathrm{nM}$ miR-296-3p antagonist or miR-296-3p mimics were mixed with Lipofectamine $2000^{\circledR}$ (Invitrogen; Thermo Fisher Scientific, Inc.), sustained for $15 \mathrm{~min}$ at room temperature then added to $1 \times 10^{6}$ cells which were seeded into six-well plates. The efficiency of the miR-296-3p antagonist and miR-296-3p mimics was detected at $48 \mathrm{~h}$ following transfection.

Silencing of ICAT in cells. ICAT siRNA (5'-GAUGGGAUC AAACCUGACA-3') and control siRNA (5'-AAUUCUCCG
AACGUGUCACGU-3') were purchased from GenePharma (Suzhou, China). In total, $50 \mathrm{nM}$ ICAT siRNA or control siRNA was transfected into $2 \times 10^{6} \mathrm{U} 251$ cells in six-well plates with Lipofectamine RNAiMax (Invitrogen; Thermo Fisher Scientific, Inc.) according to the manufacturer's protocol. The transfection efficiency was detected by western blotting $72 \mathrm{~h}$ after transfection.

Cell proliferation assay. Cell proliferation was detected using a Cell Counting Kit-8 (CCK-8) assay (Dojindo Molecular Technologies, Inc.). A total of $2 \times 10^{4}$ cells were plated into 96-well plates. At $0,24,48$ and $96 \mathrm{~h}$, a total of $10 \mu \mathrm{l} \mathrm{CCK}-8$ solution was added into the culture medium and maintained for $2 \mathrm{~h}$. Culture medium containing CCK-8 solution was subsequently transferred to a 96-well plate. Absorbance was measured at $450 \mathrm{~nm}$ and each well was analyzed using a microplate reader (Bio-Rad Laboratories, Inc.) to determine cell number.

Cell cycle analysis. Cell cycle distribution was analyzed using flow cytometry. A cell cycle assay was performed according to the manufacturers protocol of the Cell Cycle Analysis kit (Beyotime Institute of Biotechnology, Haimen, China). A total of $1 \times 10^{6}$ cells were collected, washed with cold phosphate buffered saline (PBS; Invitrogen; Thermo Fisher Scientific, Inc.) and fixed in $70 \%$ ethanol at $4^{\circ} \mathrm{C}$ for $24 \mathrm{~h}$. Cells were subsequently washed with cold PBS and stained in a propidium iodide/RNase A mixture at room temperature for $30 \mathrm{~min}$. Subsequent to incubation for $30 \mathrm{~min}$ at room temperature, the cells were analyzed using a fluorescence-activated cell sorting Caliber system (BD Biosciences). The data were analyzed with the FlowJo software V 10.0.7 (BD Biosciences).

Western blotting. Lysates were prepared from $1 \times 10^{6}$ cells using RIPA lysis buffer (Sigma Aldrich; Merck KGaA). The concentration of each sample was determined with a bicinchoninic acid Protein Assay Kit (Thermo Fisher Scientific, Inc.). Antibodies for GAPDH (mouse; G8795; 1:10,000) were purchased from Sigma Aldrich (Merck KGaA). P21 (rabbit; 2947; 1:2,000), cyclin D1 (rabbit; 2978; 1:2,000), c-Myc (rabbit; 5605; 1:2,000), AKT (rabbit; 4691; 1:2,000), phosphorylated (p-) AKT (rabbit; 4060; 1:2,000), ERK1/2 (rabbit; 4695; 1:2,000), p-ERK1/2 (rabbit; 9101; 1:2,000) antibodies were bought from Cell Signaling Technology. ICAT (rabbit; ab129011; 1:1,000) and $\beta$-catenin (rabbit, ab16051, 1:1,000) antibody was obtained from Abcam. Horseradish peroxidase-conjugated secondary antibodies against mouse (SA00001-1; 1:100,000) and rabbit (SA00001-2; 1:100,000) were obtained from Proteintech Group. Western blot was conducted following a standard procedure. $20 \mu \mathrm{g}$ protein lysate was loaded into an $8 \%$ SDS gel and separated via electrophoresis. Proteins on gel were transferred into a PVDF membrane. The membrane was blocked using 5\% non-fat milk at room temperature for $1 \mathrm{~h}$ and then incubated with the indicated primary antibody overnight at $4^{\circ} \mathrm{C}$. On the next day, the membrane was washed and incubated with the appropriate secondary antibody for $1 \mathrm{~h}$ at room temperature. Finally, membrane was developed using ECL western blotting substrate (Thermo Fisher Scientific, Inc.) and images were obtained using ImageQuant LAS 4000 (GE Healthcare Life Sciences). Western blotting data were quantified with Image J software Version.1.6.0 (National Institute of Science). 
$R N A$ extraction and reverse transcription-quantitative $P C R$ $(R T-q P C R)$. Total RNA from tissues and $1 \times 10^{6}$ cells was extracted using TRIzol Reagent (Invitrogen; Thermo Fisher Scientific, Inc.) according to the manufacturer's protocol. The quality and concentration of RNA was detected with NanoDrop 2000 (Thermo Fisher Scientific, Inc.). For detection of miR-296-3p expression, RNA was reverse transcribed to cDNA using a stem-loop primer with RevertAid First Strand cDNA kit (Thermo Fisher Scientific, Inc.). For mRNA expression analysis, RNA was reverse transcribed to first-strand cDNA using PrimeScript RT Master Mix (Takara Bio, Inc.). qPCR was performed using SYBR Premix Ex Taq kit (Takara Bio, Inc.). U6 and GAPDH served as internal controls for the semi-quantification of miR-296-3p and genes expression, respectively. The relative miR-296-3p and genes expression was calculated by the $2^{-\Delta \Delta \mathrm{Cq}}$ method (25). qPCR thermocycling conditions were as follows: Initial denaturation at $95^{\circ} \mathrm{C}$ for $30 \mathrm{sec}$, followed by 35 cycles of $95^{\circ} \mathrm{C}$ for $15 \mathrm{sec}$ and $60^{\circ} \mathrm{C}$ for $30 \mathrm{sec}$. The primer sequences were as follows: Stem-loop primer, 5'-CTCAACTGGTGTCGTGGAGTCGGCAATTCA GTTGAGGGAGAG-3'; miR-296-3p-forward, 5'-GCCGAG GAGGGTTGGGTGGA-3'; miR-296-3p-reverse, 5'-CTC AACTGGTGTCGTGGA-3'; U6-forward, 5'-CTCGCTTCG GCAGCACA-3'; U6-reverse, 5'-AACGCTTCACGAATT TGCGT-3'; ICAT-forward, 5'-CCTATGCAGGGGTGGTCA AC-3'; ICAT-reverse, 5'-CGACCTGGAAAACGCCATCA-3'; GAPDH-forward, 5'-AACGTGTCAGTGGTGGACCTG-3'; GAPDH-reverse, 5'-AGTGGGTGTCGCTGTTGAAGT-3'.

Bioinformatic analysis. The potential target genes of miR-296-3p were predicted using the online software miRanda V 2010 (http://www.microrna.org/microrna/home.do) (26). The target site prediction of all conserved miRNAs was downloaded from the software. Then, the Database for Annotation, Visualization and Integrated Discovery (https://david.ncifcrf. gov/) was used to screen for Wnt signaling related genes $(27,28)$.

Dual luciferase reporter assay. The 3'UTR of ICAT mRNA was amplified from cDNA of 293 cells followed by insertion into pmirGLO plasmid (Promega Corporation) to construct pmirGLO-ICAT 3'UTR-wild-type (WT). pmirGLO-ICAT 3'UTR-Mutant (Mut) with mutation of predicted miR-296-3p binding sites was created by introducing site mutations of pmirGLO-ICAT 3'UTR-WT using Quick site-directed mutagenesis kit (Agilent Technologies, Inc.). For dual luciferase assay, $1 \times 10^{6} \mathrm{U} 251$ cells were transfected with $2 \mu \mathrm{g}$ pmirGLO-ICAT 3'UTR-WT or pmirGLO-ICAT 3'UTR-Mut accompanied with miR-296-3p mimics or miR-NC mimics and an internal control Renilla plasmid (hRluc-neo). After $24 \mathrm{~h}$, the relative luciferase activity of each well was measured using a Dual-Glo luciferase Assay System (Promega Corporation) following the manufacture's protocol. The firefly luciferase activity was normalized to Renilla luciferase activity.

Immunofluorescence. In total, $1 \times 10^{5} \mathrm{U} 251$ cells were grown on glass slides in 24-well plates, transfected with miR-NC antagonist or miR-296-3p antagonist and incubated for $48 \mathrm{~h}$ at $37^{\circ} \mathrm{C}$. Wells were then washed with PBS and treated with $4 \%$ paraformaldehyde for $30 \mathrm{~min}$ at room temperature. Cells were subsequently permeabilized and blocked using PBS containing
$0.1 \%$ Triton $\mathrm{X}-100$, in $1 \%$ bovine serum albumin, for $1 \mathrm{~h}$ at room temperature. A $\beta$-catenin (rabbit; 1:100; cat. no. ab16051; Abcam) antibody was used as the primary antibody to incubate the glass slides for $2 \mathrm{~h}$ at room temperature, and Alexa Fluor 594-conjugated secondary antibody (1:50,000; cat. no. R37117; Invitrogen; Thermo Fisher Scientific, Inc.) was applied to detect fluorescence ( $1 \mathrm{~h}$ at room temperature). DAPI (Vector Laboratories, Inc.) was finally added into the glass slides to stain cell nuclei. The slides were observed and the representative images were captured using the Leica DM5000 B microscope (Leica Microsystems, Inc.).

Statistical analysis. All data were statistically analyzed using GraphPad Prism 7 (GraphPad Software, Inc.) and presented as the mean \pm standard deviation. Differences between two groups were compared using a paired Student's t-test. All experiments were repeated at least three times. For comparison among three groups, the data were firstly analyzed using a one-way analysis of variance, followed by a Newman Keul's test. Pearson's correlation analysis was used for the analysis of the correlation between miR-296-3p expression and ICAT mRNA levels in GBM tissues. $\mathrm{P}<0.05$ was considered to indicate a statistically significant result.

\section{Results}

miR-296-3p is upregulated in GBM tissues. To determine the expression of miR-296-3p in GBM tissues, a total of 10 normal brain tissues and 40 GBM tissues (10 grade I, 10 grade II, 10 grade III and 10 grade IV) were collected, and miR-296-3p expression was determined using a reverse transcription-quantitative polymerase chain reaction (RT-qPCR). miR-296-3p expression was demonstrated to be significantly increased in GBM tissues compared with normal tissues $(\mathrm{P}<0.01$; Fig. 1A). Additionally, miR-296-3p was indicated not to be overexpressed in GBM tissues from patients at grade II, but significantly increased in GBM tissues from patients at grade III and grade IV compared with normal tissues $(\mathrm{P}<0.01$; Fig. 1B).

\section{Antagonization of miR-296-3p suppresses cell proliferation} and alters cell cycle distribution in U251 cells. To study the function of miR-296-3p in GBM cells, miR-296-3p expression was downregulated, using transfection with a miR-296-3p antagonist, in U251 cells. Cells transfected with the miR-296-3p antagonist demonstrated a significant 4-fold decrease in miR-296-3p expression compared with those transfected with the negative control $(\mathrm{P}<0.001 ;$ Fig. $2 \mathrm{~A})$. The results of the CCK-8 assay indicated that miR-296-3p downregulation significantly inhibited U251 cell growth ( $\mathrm{P}<0.01$; Fig. $2 \mathrm{~B})$. Additionally, flow cytometry revealed that the miR-296-3p antagonist induced a significant increase of cells enriched in the G0/G1 phase compared with the control cells, indicating the redistribution of the cell cycle $(\mathrm{P}<0.001$; Fig. $2 \mathrm{C}$ and $\mathrm{D})$. Western blot analysis was performed to detect a number of key genes that have been indicated to be associated with the G1/S checkpoint. The expression levels of p21, an inhibitor of cell cycle progression, were demonstrated to be significantly increased following transfection with the miR-296-3p antagonist compared with the negative control $(\mathrm{P}<0.01)$. Furthermore, 
A

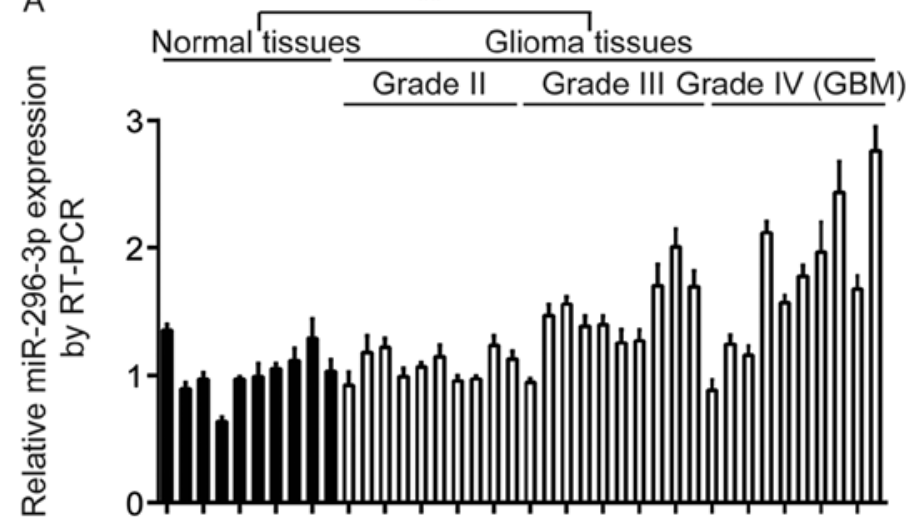

B

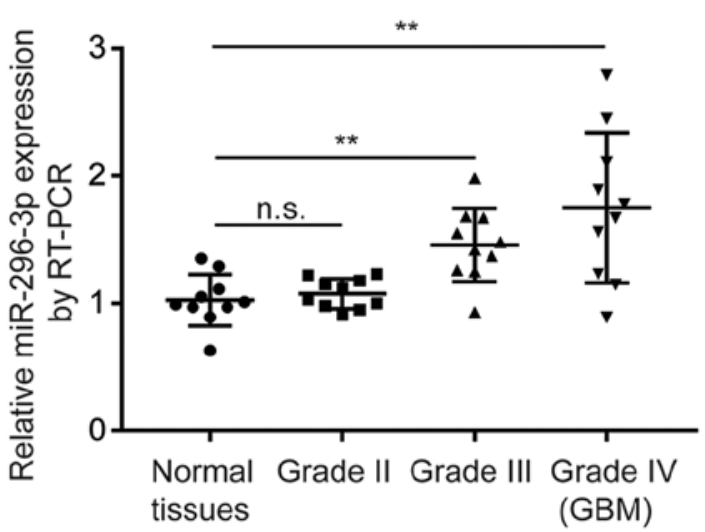

Figure 1. miR-296-3p was overexpressed in GBM tissues. (A) Compared with 10 human normal brain tissues, miR-296-3p levels were elevated in 30 GBM tissues. (B) In comparison with 10 normal brain tissues, miR-296-3p levels were increased in GBM tissues from patients at grade III and IV but not grade II. ${ }^{* *} \mathrm{P}<0.01$ with comparisons shown by lines. GBM, glioblastoma multiforme; miR, microRNA; n.s., non-significant; RT-qPCR, reverse transcription-quantitative polymerase chain reaction.

cyclin D1 expression levels were revealed to be significantly decreased following transfection with miR-296-3p antagonist compared with the negative control $(\mathrm{P}<0.001$; Fig. $2 \mathrm{E}$ and $\mathrm{F})$. These results suggested that miR-296-3p may promote cell cycle progression to facilitate GBM cell proliferation.

miR-296-3p negatively regulates ICAT expression in GBM cells. To investigate the mechanism of miR-296-3p in GBM cells, miRanda was used to predict the potential target genes of miR-296-3p. Among these target genes, Database for Annotation, Visualization and Integrated Discovery software was used and the results demonstrated that the 3'UTR of ICAT, a key regulator of Wnt signaling, could complementary bind to miR-296-3p (data not shown). ICAT is a negative regulator of the Wnt signaling pathway and is considered to be a tumor suppressor in GBM cells (20). With similar results observed in U251 cells, the transfection of miR-296-3p antagonist also significantly decreased miR-296-3p expression levels in U138MG cells ( $\mathrm{P}<0.001$; Fig. 3A). miR-296-3p downregulation was also indicated to significantly increase ICAT mRNA expression levels in U251 and U138MG cells $(\mathrm{P}<0.001$; Fig. 3B). Additionally, ICAT protein expression levels were also significantly increased following transfection with an miR-296-3p antagonist ( $\mathrm{P}<0.01$; Fig. $3 \mathrm{C}$ and D). miRNA mimics are chemically synthesized miRNAs, and following transfection into cells, miRNA mimics have been revealed to mimic the function of a miRNA (12). Therefore, miR-296-3p mimics were used to overexpress miR-296-3p in U251 and U138MG cells. Transfection of miR-296-3p mimics resulted in a 2-fold increase in miR-296-3p expression levels in U251 and U138MG cells $(\mathrm{P}<0.01$; Fig. $3 \mathrm{E})$. In contrast, the overexpression of miR-296-3p significantly decreased ICAT expression at the mRNA and protein levels $(\mathrm{P}<0.05$; Fig. $3 \mathrm{~F}-\mathrm{H})$.

miR-296-3p regulates the ICAT-regulated signaling network in GBM cells. The overactivation of phosphoinositide-3-kinase (PI3K)-protein kinase B (AKT), mitogen-activated protein kinase-extracellular signal-regulated kinase (ERK) and Wnt signaling pathways serves an important function in cell proliferation and cell cycle regulation in GBM cells (29-31). Using western blot analysis, $\beta$-catenin, a signal transducer of the Wnt signaling pathway, was indicated to be significantly decreased following the downregulation of miR-296-3p compared with the negative control $(\mathrm{P}<0.01)$, while $\mathrm{p}-\mathrm{AKT}$ and $\mathrm{p}-\mathrm{ERK} 1 / 2$ expression did not differ (Fig. 4A and B). Additionally, the expression of Wnt signaling target gene c-Myc was also significantly decreased in cells transfected with miR-296-3p antagonist compared with the negative control $(\mathrm{P}<0.01$; Fig. 4A and B). Furthermore, using immunofluorescence, it was observed that $\beta$-catenin was located in the nucleus of U251 cells (Fig. 4C). Transfection of a miR-296-3p antagonist resulted in the translocation of $\beta$-catenin from the nucleus to the cytoplasm of cells (Fig. 4C). These results suggested that miR-296-3p may activate the Wnt signaling pathway via the regulation of ICAT.

miR-296-3p directly binds to the 3'UTR of ICAT mRNA. To assess whether miR-296-3p directly regulated ICAT expression, miRanda was used to align the sequences of miR-296-3p and ICAT 3'UTR. A complementary site was observed between miR-296-3p and ICAT 3'UTR (Fig. 5A). Luciferase reporter assays were performed to functionally verify whether miR-296-3p directly targets ICAT in U251 cells. Wild type ICAT-3'UTR resulted in significantly decreased luciferase activity relative to mutated ICAT-3'UTR in U251 cells co-transfected with miR-296-3p mimics compared with the negative control $(\mathrm{P}<0.01$; Fig. $5 \mathrm{~B})$, indicating that ICAT was a target gene of miR-296-3p in U251 cells. Similar results were also observed in U138MG cells ( $\mathrm{P}<0.01$; Fig. 5C).

miR-296-3p regulates Wnt signaling via ICAT to control glioma cell proliferation. ICAT small-interfering RNA was transfected into U251 cells to significantly downregulate ICAT expression compared with the control $(\mathrm{P}<0.0001$; Fig. 6A and B). Silencing ICAT significantly reversed the downregulation of $\beta$-catenin and $\mathrm{c}-\mathrm{Myc}$ that was induced by miR-296-3p antagonist ( $\mathrm{P}<0.01$; Fig. 6C and D). Furthermore, miR-296-3p downregulation-induced cell growth arrest was also demonstrated to be significantly reversed upon ICAT silencing in U251 cells ( $\mathrm{P}<0.0001$; Fig. 6E). 

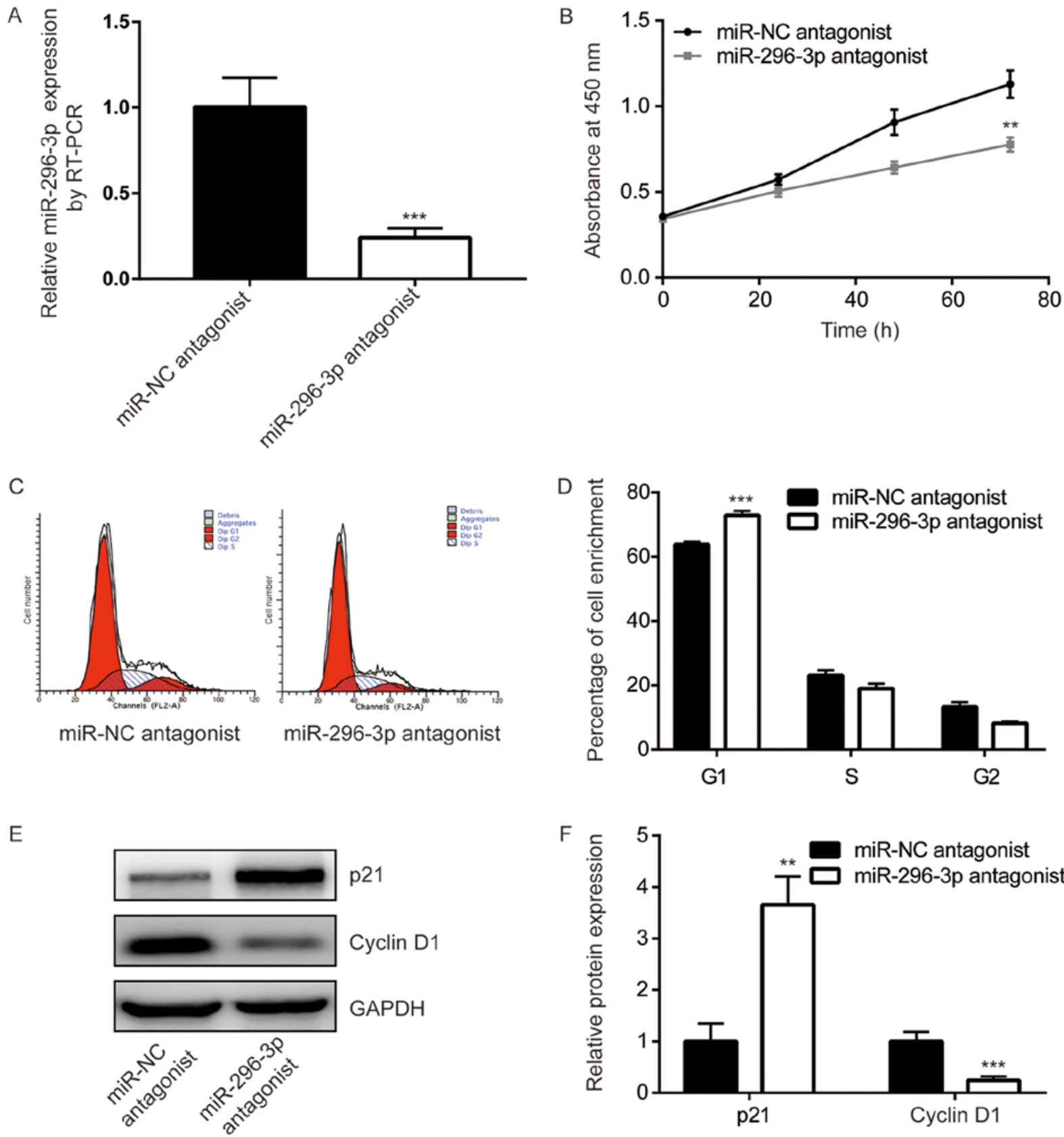

Figure 2. miR-296-3p regulated cell growth and cell cycle in U251 cells. (A) Transfection of miR-296-3p antagonist reduced miR-296-3p expression in U251 cells. (B) Transfection of miR-296-3p antagonist inhibited cell proliferation in U251 cells. (C) miR-296-3p antagonist induced the redistribution of cell cycle of U251 cells. (D) Quantification analysis of cells accumulated in G1, S and G2 phases. (E) Western blot analysis revealed that p21 expression was elevated and cyclin D1 was decreased in response to miR-296-3p downregulation. (F) Quantification of p21 and cyclin D1 protein expression shown in. (E) **P $<0.01$ and ${ }^{* * *} \mathrm{P}<0.001$ vs. miR-NC antagonist; RT-qPCR, reverse transcription-quantitative polymerase chain reaction; NC, negative control; miR, microRNA.

miR-296-3p level is negatively correlated with ICAT levels in GBM tissues. Subsequently, the association between miR-296-3p and ICAT expression was assessed in the present study. RT-qPCR indicated that ICAT mRNA levels were significantly increased in GBM tissues compared with normal brain tissues $(\mathrm{P}<0.0001$; Fig. 7A). Additionally, significantly decreased ICAT expression was observed in GBM tissues from patients at all grades in comparison with normal brain tissues ( $\mathrm{P}<0.05$; Fig. 7B). Pearson correlation analysis indicated a strong and significant negative correlation between miR-296-3p expression and ICAT mRNA levels in GBM tissues ( $r=-0.478, P=0.007$; Fig. 7C).

\section{Discussion}

Accumulating evidence has suggested that miRNAs are associated with the initiation and development of GBM (32-34). A number of miRNAs have been demonstrated to be aberrantly expressed, and are indicated to be promising biomarkers for patients with GBM $(35,36)$. miR-296-3p was reported to be downregulated in GBM tissues from 30 patients compared with 12 normal brains, and the downregulation of miR-296-3p was indicated to promote the development of multi-drug resistance (17). However, one other study indicated that miR-296-3p is negatively regulated by neurofibromatosis 2 in 
A

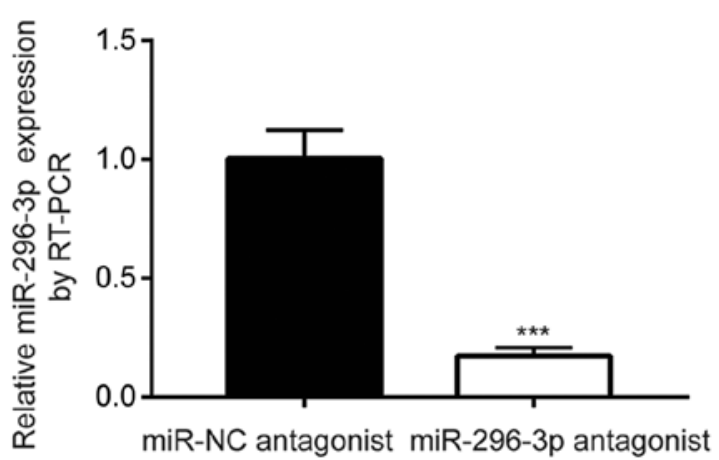

B

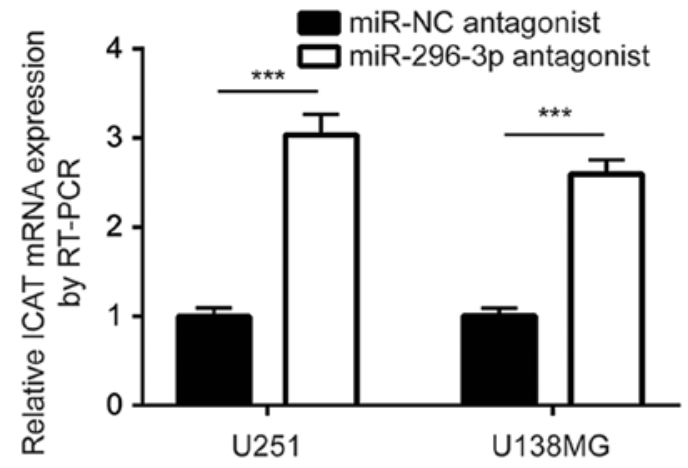

C

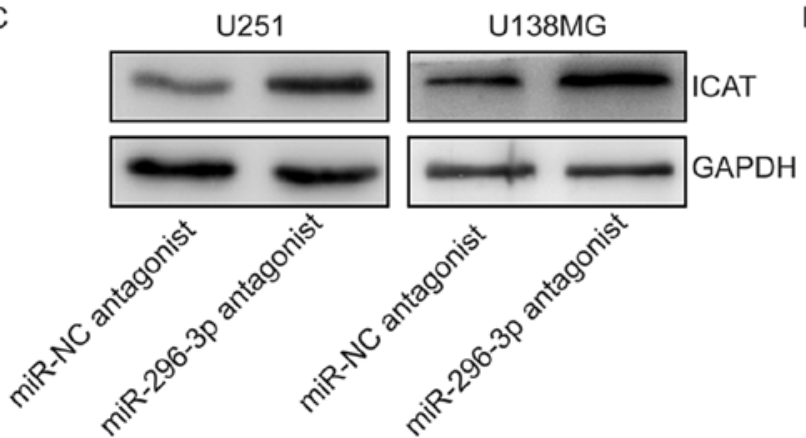

D

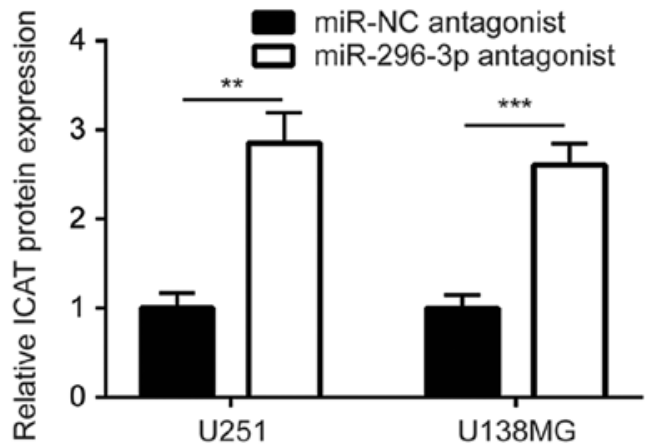

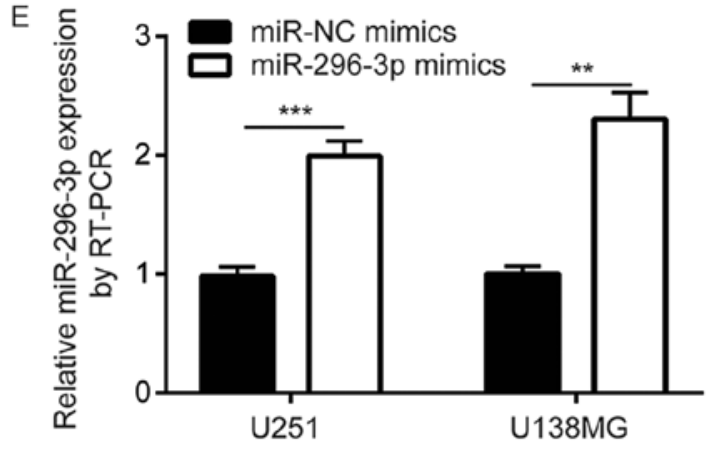

G

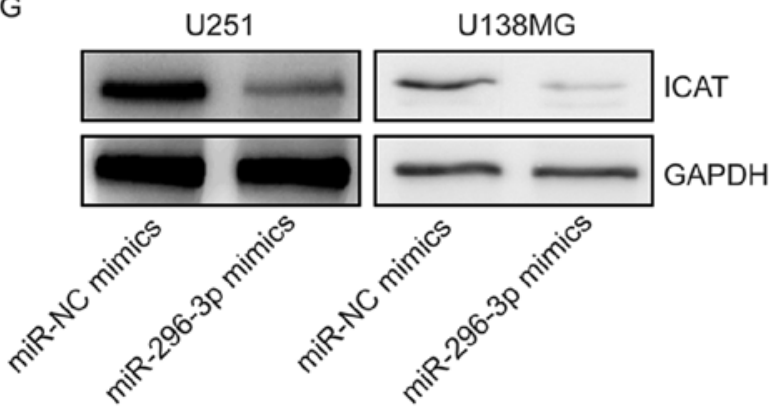

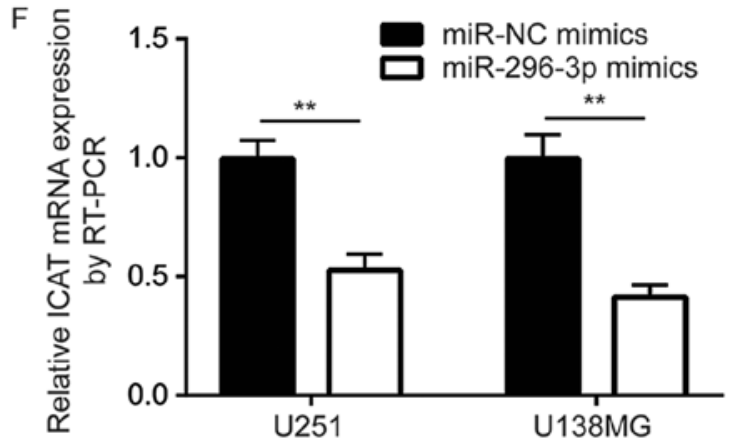

$\mathrm{H}$

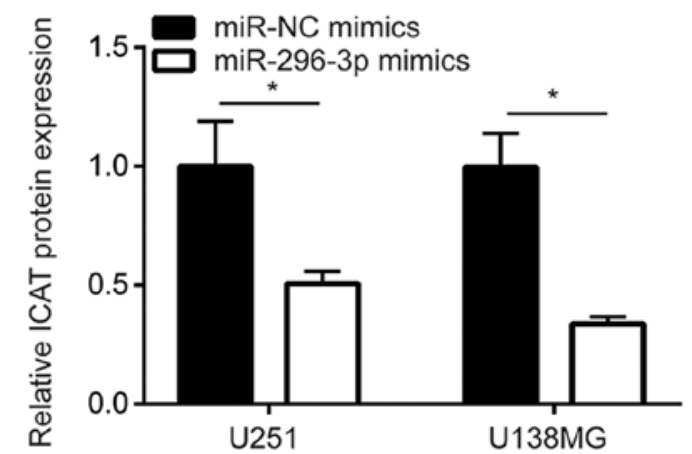

Figure 3. miR-296-3p negatively regulated ICAT expression in U251 and U138MG cells. (A) Transfection of miR-296-3p antagonist decreased miR-296-3p mRNA expression levels in U138MG cells. (B) Transfection of miR-296-3p antagonist increased ICAT mRNA levels in U251 and U138MG cells. (C) Transfection of miR-296-3p antagonist increased ICAT protein expression in U251 and U138MG cells. (D) Quantification of ICAT protein expression levels shown in (C). (E) Transfection of miR-296-3p mimics increased miR-296-3p levels in U251 and U138MG cells. (F) Transfection of miR-296-3p mimics decreased ICAT mRNA levels in U251 and U138MG cells. (G) miR-296-3p mimics decreased ICAT protein expression in U251 and U138MG cells. (H) Quantification of ICAT protein expression levels in $(\mathrm{G}) .{ }^{*} \mathrm{P}<0.05,{ }^{* *} \mathrm{P}<0.01$ and ${ }^{* * * *} \mathrm{P}<0.001$ with comparisons shown by lines. miR, microRNA; ICAT, inhibitor of $\beta$-catenin and $\mathrm{T}$ cell factor; NC, negative control; RT-qPCR, reverse transcription-quantitative polymerase chain reaction.

GBM cells, and analysis of The Cancer Genome Atlas GBM dataset demonstrated that a high expression of miR-296-3p was associated with the short overall survival time of patients with GBM, in a large cohort (16). In the present study, an elevation of miR-296-3p was observed in GBM tissues, particularly in GBM tissues from patients at late grades compared with normal brain tissues, which supports the oncogenic function of miR-296-3p, as a high expression of miR-296-3p predicts poor 
A
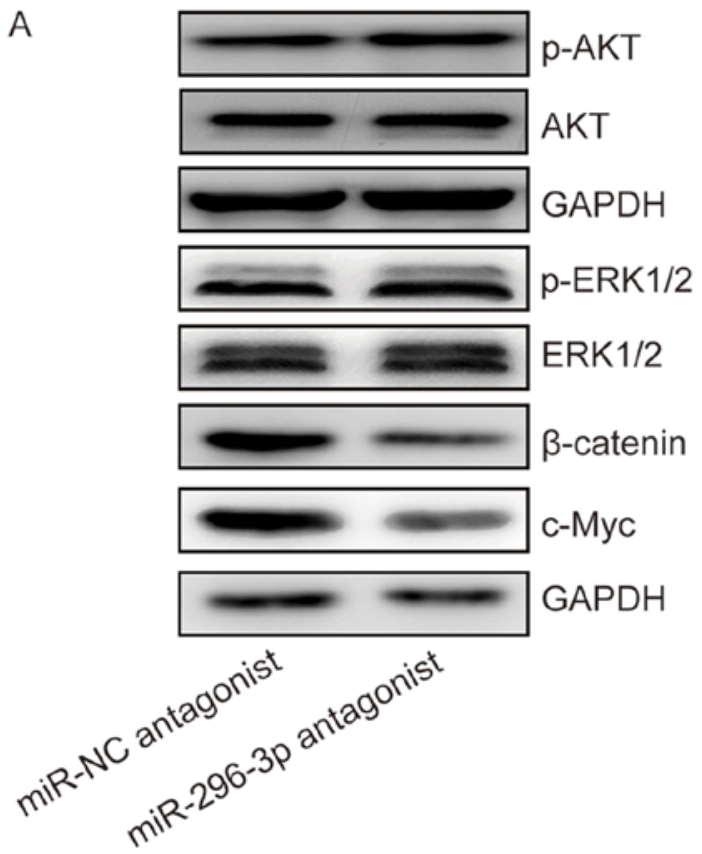

C
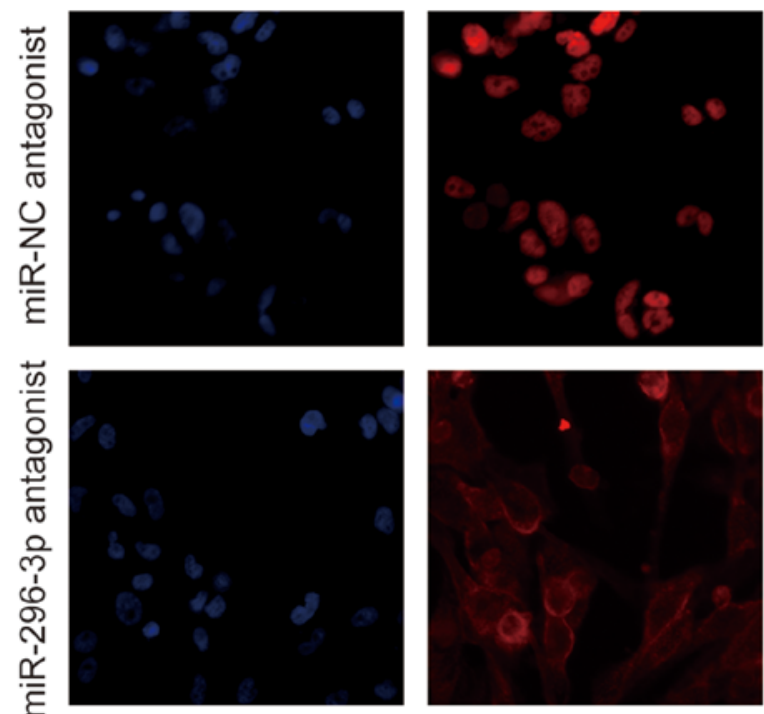

DAPI
B

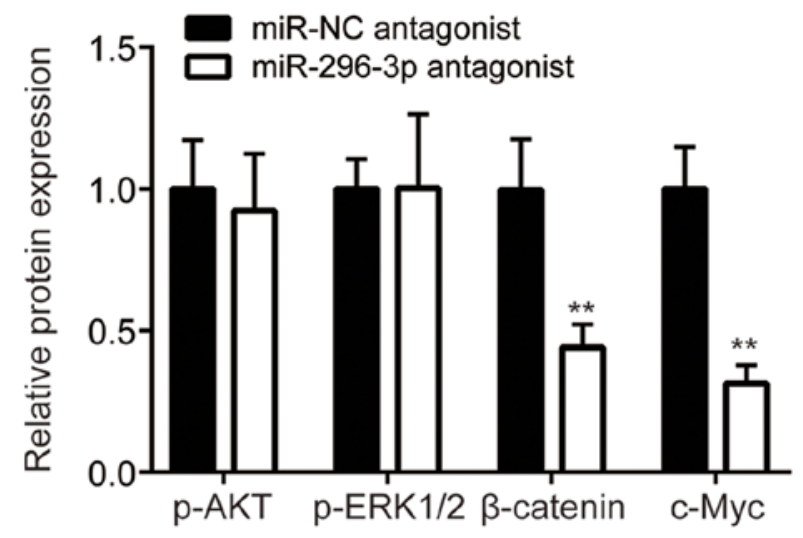

Figure 4. miR-296-3p regulated Wnt signaling activity in U251 cells. (A) Western blot analysis indicated that p-AKT and p-ERK1/2 expression was not changed, while $\beta$-catenin and its target gene c-Myc was downregulated following miR-296-3p downregulation. (B) Quantification of protein expression levels shown in (A). (C) Immunofluorescence was used to detect the subcellular location of $\beta$-catenin in U251 cells. Scale bar, $20 \mu \mathrm{m}$. ${ }^{* *} \mathrm{P}<0.01 \mathrm{vs}$. miR-NC. p-, phosphorylated; AKT, protein kinase B; ERK1/2, extracellular signal-regulated kinase 1/2; NC, negative control; miR, microRNA.

survival in GBM. The downregulation of miR-296-3p levels in U251 cells was also indicated to inhibit cell proliferation and alter the cell cycle distribution. Additionally, the expression of p21 and cyclin D1 differed following the downregulation of miR-296-3p. The results of the present study suggested that miR-296-3p may promote the proliferation of GBM cells via the regulation of cell cycle progression.

The Wnt/ $\beta$-catenin signaling pathway is an important pathway in the maintenance of stem cells, and has been indicated to be aberrantly activated in a number of cancer types, including in GBM (37-39). Through blocking the binding of TCF to $\beta$-catenin, ICAT has been observed to function as an inhibitor of the Wnt signaling pathway (18). However, the function of ICAT in carcinogenesis remains to be controversial.
A previous study demonstrated decreased ICAT expression in GBM tissues and a tumor suppressor function of ICAT in GBM cells (22). In the present study, through the analysis of ICAT mRNA expression in GBM tissues and normal tissues, the downregulation of ICAT in GBM tissues was also observed, particularly in tissues from patients at grade III and IV. The expression of ICAT was negatively correlated with miR-296-3p in GBM tissues. Inconsistently, ICAT expression was decreased in grade II glioma, whereas miR-296-3p levels were not increased, which may reflect the complexity of ICAT regulation in GBM, suggesting that ICAT may be regulated by other mechanisms in patients with grade II GBM. In cells, the deregulation of a number of miRNAs was reported to promote the aberrant expression of ICAT $(21,23,40)$. miR-296-3p was 
A
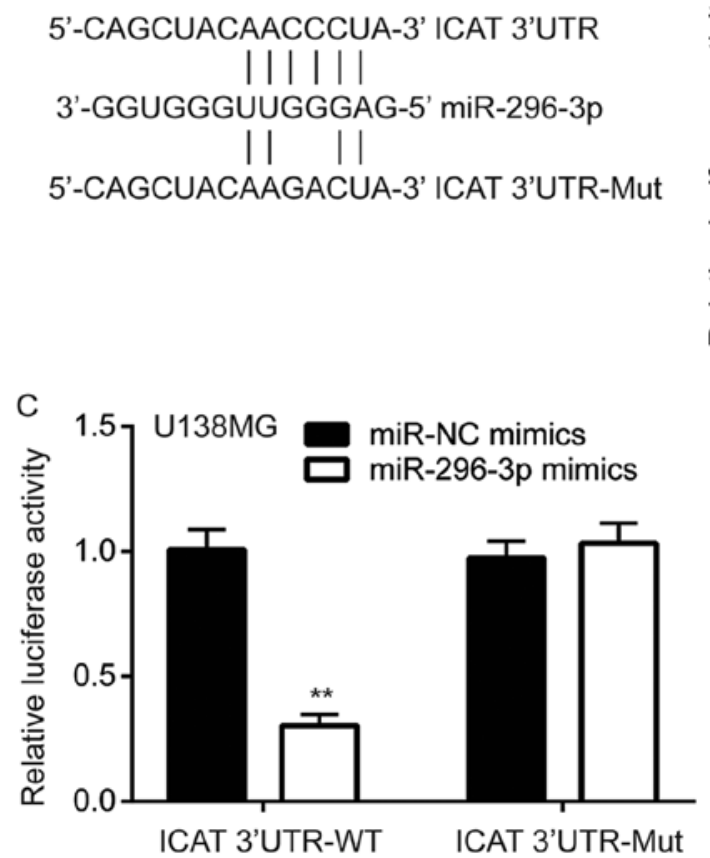

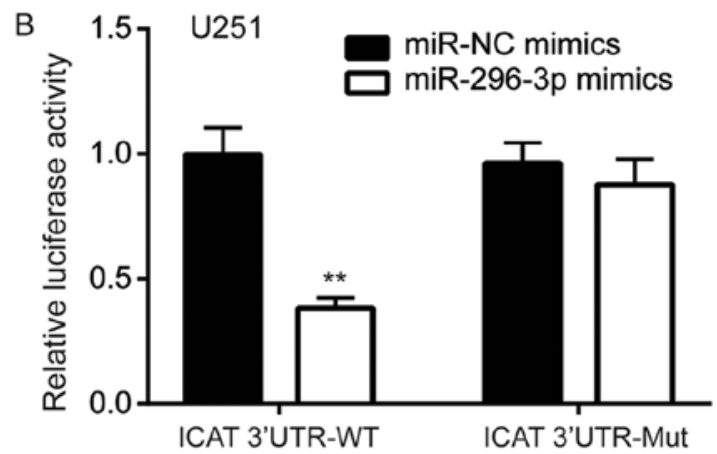

Figure 5. ICAT was a target gene of miR-296-3p in U251 cells. (A) Sequence alignment of ICAT 3'UTR and miR-296-3p indicated a potential complementary binding site. (B) A dual luciferase reporter assay indicated that miR-296-3p mimics decreased the luciferase activity of U251 cells transfected with ICAT 3'UTR-WT but not ICAT 3'UTR mutant. (C) A dual luciferase reporter assay indicated that miR-296-3p mimics decreased the luciferase activity of U138MG cells transfected with ICAT 3'UTR-WT but not ICAT 3 'UTR mutant. ${ }^{* * *} \mathrm{P}<0.01$ vs. miR-NC. miR, microRNA; ICAT, inhibitor of $\beta$-catenin and T cell factor; NC, negative control; WT, wild type; Mut, mutated type; 3'UTR, 3'untranslated region.

A

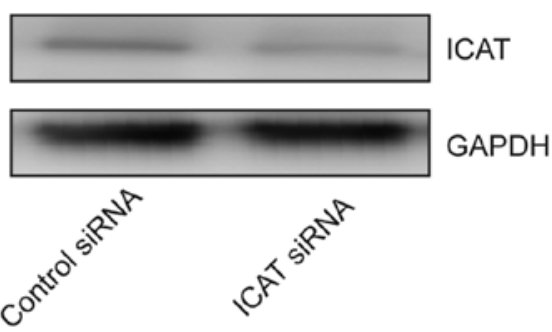

C
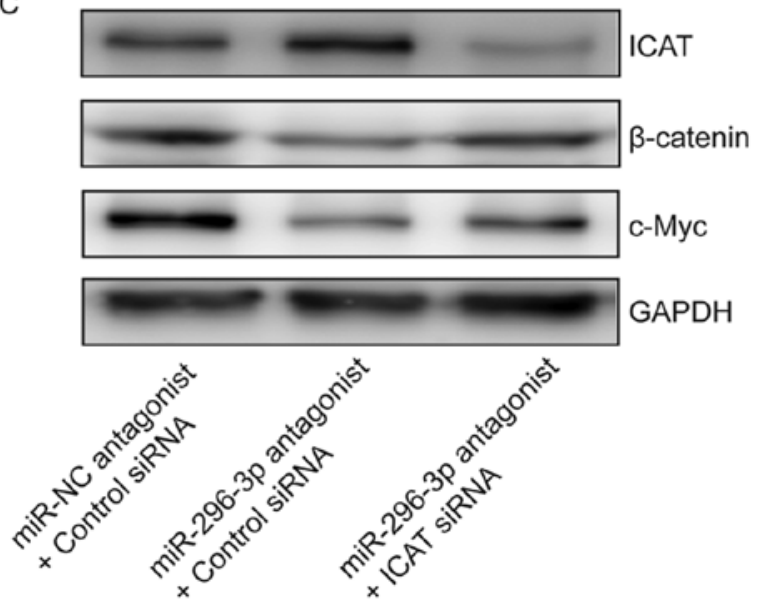

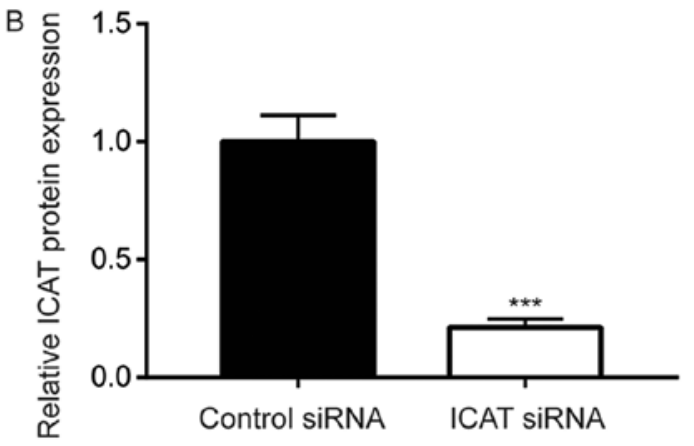

D

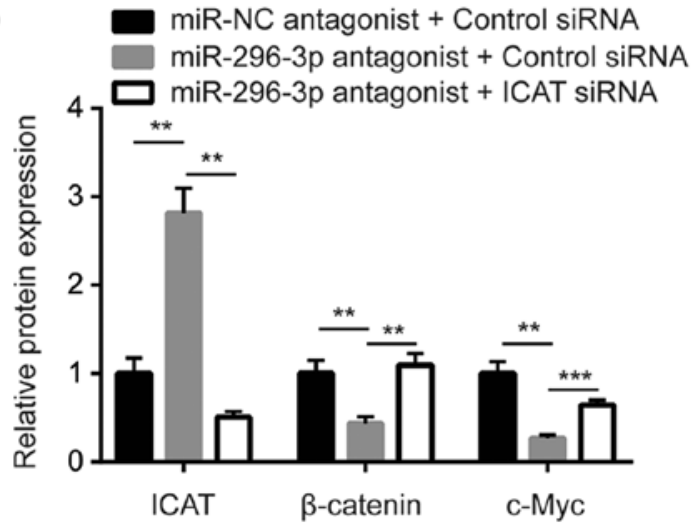

Figure 6. miR-296-3p regulated glioma cell proliferation via targeting ICAT. (A) Western blot analysis revealed that the transfection of ICAT siRNA decreased ICAT protein expression in U251 cells. (B) Quantification analysis of ICAT protein expression levels shown in (A). (C) Western blot analysis revealed that the silencing of ICAT reversed the downregulation of $\beta$-catenin and c-Myc protein expression induced by the miR-296-3p antagonist. (D) Quantification analysis of $\beta$-catenin and c-Myc protein expression levels shown in (C). 


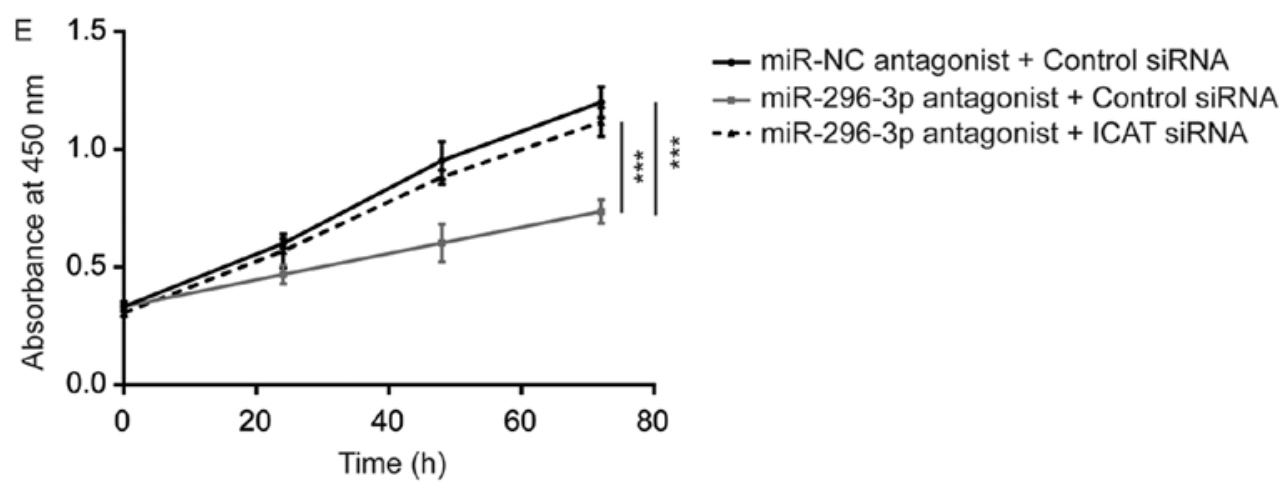

Figure 6. Continued. (E) A cell proliferation assay revealed that miR-296-3p antagonist induced cell growth arrest in U251 cells which was reversed with ICAT silencing. ${ }^{* *} \mathrm{P}<0.01$ and ${ }^{* * * *} \mathrm{P}<0.001$ with comparisons shown by lines. siRNA, small interfering RNA; miR, microRNA; ICAT, inhibitor of $\beta$-catenin and T cell factor; NC, negative control.
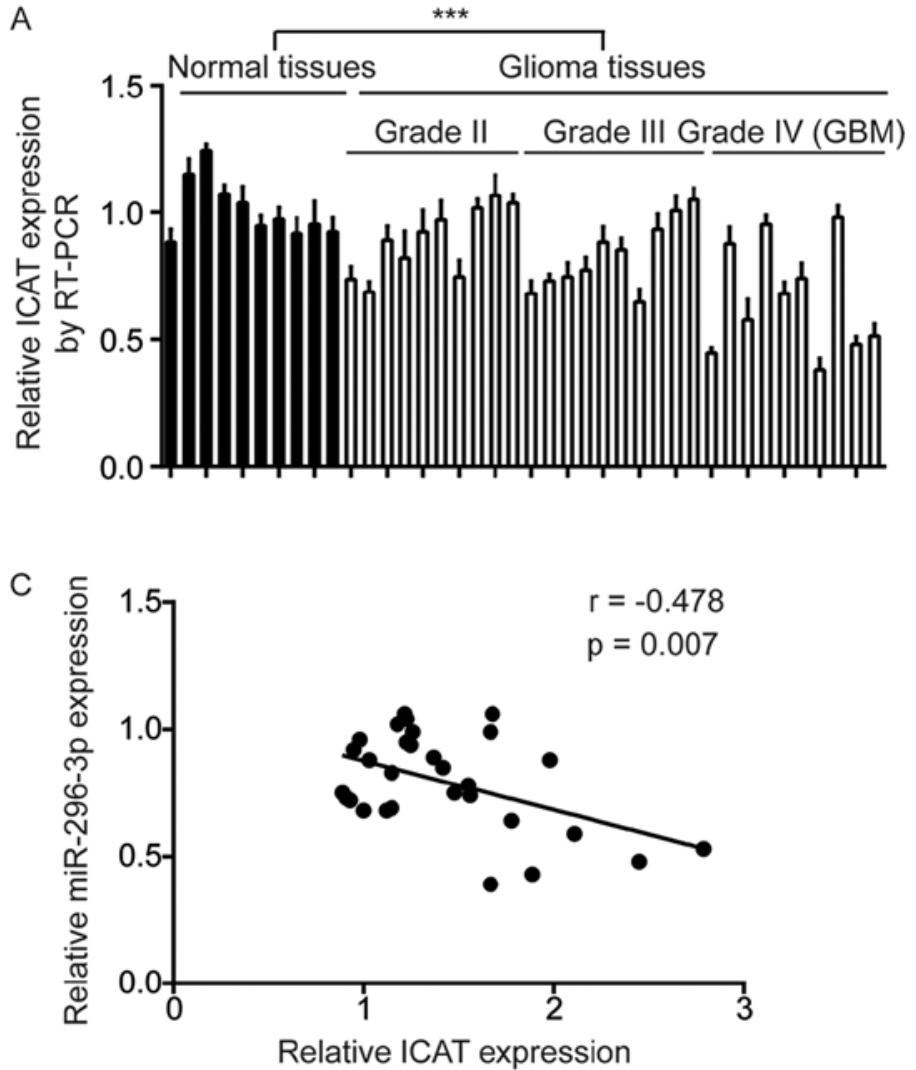

B

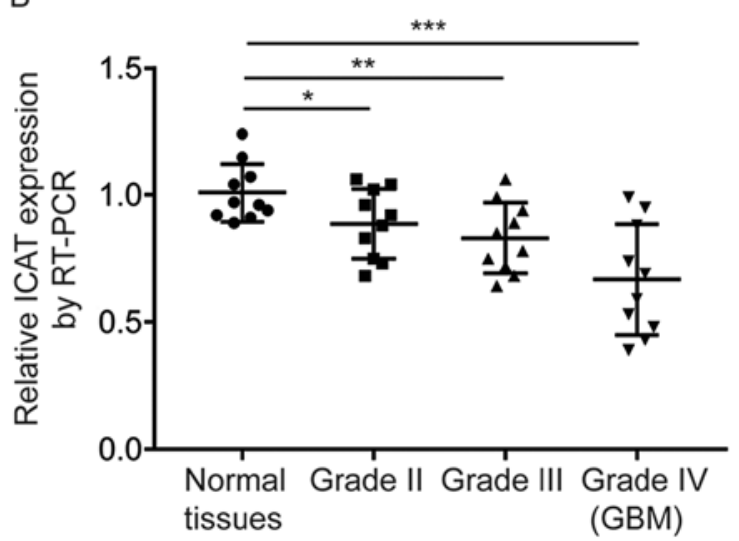

Figure 7. ICAT mRNA levels negatively correlated with miR-296-3p expression in GBM tissues (A) Compared with 10 human normal brain tissues, ICAT levels were decreased in $30 \mathrm{GBM}$ tissues. (B) In comparison with 10 normal brain tissues, ICAT levels were decreased in GBM tissues from patients at grade II, III and IV. (C) Pearson analysis indicated that miR-296-3p expression was negatively correlated with ICAT mRNA levels in GBM tissues. ${ }^{*} \mathrm{P}<0.05$, ${ }^{* *} \mathrm{P}<0.01$ and ${ }^{* * *} \mathrm{P}<0.001$ with comparisons shown by lines. ICAT, inhibitor of $\beta$-catenin and $\mathrm{T}$ cell factor; GBM, glioblastoma multiforme; miR, microRNA; RT-qPCR, reverse transcription-quantitative polymerase chain reaction.

revealed to negatively regulate ICAT expression in U251 cells. Using miRanda, ICAT was predicted as a potential target gene of miR-296-3p, which was further verified using a dual luciferase reporter assay in two glioblastoma cell lines. Additionally, miR-296-3p downregulation was observed to result in the decreased expression of $\beta$-catenin and its target genes (cyclin D1 and c-Myc) in U251 cells, suggesting that miR-296-3p may activate the Wnt signaling pathway via the repression of ICAT expression. The cyclin D1-cyclin-dependent kinase $4 / 6$ complex is important for cell cycle progression in the G1 phase (41). The overexpression of cyclin D1 has been observed in a number of cancer types and has been indicated to promote cell proliferation (42). Cyclin D1 protein expression decreases as cells enter the $\mathrm{S}$ phase, but the expression of cyclin D1 is still important for passing the G0/G1 phase, and the low expression of cyclin D1 will result in cell accumulation in the G1 phase (41). The results of the present study suggested that miR-296-3p may positively regulate cyclin D1 expression via Wnt signaling to control GBM cell cycle progression and promote GBM cell growth. miR-296-3p has 
been suggested to target MK2 and PRKCA in nasopharyngeal carcinoma and lung adenocarcinoma, respectively $(43,44)$. The downregulation of MAPK activated protein kinase 2 and protein kinase $\mathrm{C} \alpha$ was observed to inhibit PI3K/AKT and Ras signaling, resulting in the downregulation of c-Myc $(43,44)$. In the present study, the expression of key proteins of PI3K/AKT, Ras and Wnt signaling was determined following the downregulation of miR-296-3p in GBM. The downregulation of Wnt signaling was only observed in GBM cells $(43,44)$, but the observation excluded the previously reported regulatory association between miR-296-3p and c-Myc. The results of the present study indicated that miR-296-3p promoted c-Myc expression via activating the Wnt signaling. However, the association between miR-296-3p and Wnt, PI3K/AKT and Ras signaling was only assessed in U251 cells. Due to the complexity of the signaling network in glioblastoma, further studies should investigate the potential function of miR-296-3p on the signaling network in two glioblastoma cell lines.

In conclusion, the present study revealed that miR-296-3p was elevated in GBM tissues and promoted cell proliferation in GBM cells by suppressing ICAT. Therefore, the results of the present study identified a novel molecular mechanism in which miR-296-3p was overexpressed in GBM tissues to activate the Wnt signaling pathway and indicated that miR-296-3p may be a novel biomarker and therapeutic target that can be used in GBM.

\section{Acknowledgements}

Not applicable.

\section{Funding}

No funding was received.

\section{Availability of data and materials}

The datasets used and/or analyzed during the current study are available from the corresponding author on reasonable request.

\section{Authors' contributions}

HF provided the concept and designed the experiments of the study. JZ and GD collected the clinical samples, acquired and analyzed the data. JZ also designed and supervised the study. HF prepared, edited and reviewed the manuscript.

\section{Ethics approval and consent to participate}

All patients provided written informed consent prior to the study and the Ethics Committee of North Sichuan Medical College supervised and ethically approved the present study.

\section{Patient consent for publication}

All patients provided written informed consent to participate the study and agreed to publish data presented in the paper.

\section{Competing interests}

The authors declare that they have no competing interests.

\section{References}

1. Gladson CL, Prayson RA and Liu WM: The pathobiology of glioma tumors. Annu Rev Pathol 5: 33-50, 2010.

2. Zeng A, Hu Q, Liu Y, Wang Z, Cui X, Li R, Yan W and You Y: IDH1/2 mutation status combined with Ki-67 labeling index defines distinct prognostic groups in glioma. Oncotarget 6: 30232-30238, 2015.

3. Van Gool S, Maes W, Ardon H, Verschuere T, Van Cauter S and De Vleeschouwer S: Dendritic cell therapy of high-grade gliomas. Brain Pathol 19: 694-712, 2009.

4. Stupp R, Mason WP, van den Bent MJ, Weller M, Fisher B, Taphoorn MJ, Belanger K, Brandes AA, Marosi C, Bogdahn U, et al: Radiotherapy plus concomitant and adjuvant temozolomide for glioblastoma. N Engl J Med 352: 987-996, 2005.

5. Cai T, Liu Y and Xiao J: Long noncoding RNA MALAT1 knockdown reverses chemoresistance to temozolomide via promoting microRNA-101 in glioblastoma. Cancer Med 7: 1404-1415, 2018.

6. Wang Z, Xu X, Liu N, Cheng Y, Jin W, Zhang P, Wang X, Yang H, Liu $\mathrm{H}$ and Tu Y: SOX9-PDK1 axis is essential for glioma stem cell self-renewal and temozolomide resistance. Oncotarget 9: 192-204, 2017.

7. Sethi A and Sholl LM: Emerging evidence for MicroRNAs as regulators of cancer stem cells. Cancers (Basel) 3: 3957-3971, 2011.

8. Bartel DP: MicroRNAs: Genomics, biogenesis, mechanism, and function. Cell 116: 281-297, 2004.

9. Mendell JT: MicroRNAs: Critical regulators of development, cellular physiology and malignancy. Cell Cycle 4: 1179-1184, 2005.

10. Markopoulos GS, Roupakia E, Tokamani M, Alabasi G, Sandaltzopoulos R, Marcu KB and Kolettas E: Roles of NF-kB signaling in the regulation of miRNAs impacting on inflammation in cancer. Biomedicines 6: E40, 2018.

11. Li S, Chowdhury R, Liu F, Chou AP, Li T, Mody RR, Lou JJ, Chen W, Reiss J, Soto H, et al: Tumor-suppressive miR148a is silenced by $\mathrm{CpG}$ island hypermethylation in IDH1-mutant gliomas. Clin Cancer Res 20: 5808-5822, 2014.

12. Zhang R, Luo H, Wang S, Chen W, Chen Z, Wang HW, Chen Y, Yang J, Zhang X, Wu W, et al: MicroRNA-377 inhibited proliferation and invasion of human glioblastoma cells by directly targeting specificity protein 1. Neuro Oncol 16: 1510-1522, 2014.

13. Zhang Y, Dutta A and Abounader R: The role of microRNAs in glioma initiation and progression. Front Biosci (Landmark Ed) 17: 700-712, 2012.

14. Sumazin P, Yang X, Chiu HS, Chung WJ, Iyer A, Llobet-Navas D, Rajbhandari P, Bansal M, Guarnieri P, Silva J and Califano A: An extensive microRNA-mediated network of RNA-RNA interactions regulates established oncogenic pathways in glioblastoma. Cell 147: 370-381, 2011.

15. Würdinger T, Tannous BA, Saydam O, Skog J, Grau S, Soutschek J, Weissleder R, Breakefield XO and Krichevsky AM: miR-296 regulates growth factor receptor overexpression in angiogenic endothelial cells. Cancer Cell 14: 382-393, 2008.

16. Lee H, Hwang SJ, Kim HR, Shin CH, Choi KH, Joung JG and Kim HH: Neurofibromatosis 2 (NF2) controls the invasiveness of glioblastoma through YAP-dependent expression of CYR61/CCN1 and miR-296-3p. Biochim Biophys Acta 1859: 599-611, 2016.

17. Bai Y, Liao H, Liu T, Zeng X, Xiao F, Luo L, Guo H and Guo L: MiR-296-3p regulates cell growth and multi-drug resistance of human glioblastoma by targeting ether-à-go-go (EAG1). Eur J Cancer 49: 710-724, 2013.

18. Jiang Y, Ren W, Wang W, Xia J, Gou L, Liu M, Wan Q, Zhou L, Weng Y, He T and Zhang Y: Inhibitor of $\beta$-catenin and TCF (ICAT) promotes cervical cancer growth and metastasis by disrupting E-cadherin/ $\beta$-catenin complex. Oncol Rep 38: 2597-2606, 2017.

19. Koyama T, Tago K, Nakamura T, Ohwada S, Morishita Y, Yokota $\mathbf{J}$ and Akiyama T: Mutation and expression of the beta-catenin-interacting protein ICAT in human colorectal tumors. Jpn J Clin Oncol 32: 358-362, 2002.

20. Imai M, Nakamura T, Akiyama $T$ and Horii $A$ : Infrequent somatic mutations of the ICAT gene in various human cancers with frequent $1 \mathrm{p}-\mathrm{LOH}$ and/or abnormal nuclear accumulation of beta-catenin. Oncol Rep 12: 1099-1103, 2004.

21. Zhang Y,Li T, Guo P, Kang J, Wei Q, Jia X, Zhao W, Huai W, Qiu Y, Sun L and Han L: MiR-424-5p reversed epithelial-mesenchymal transition of anchorage-independent HCC cells by directly targeting ICAT and suppressed HCC progression. Sci Rep 4: 6248, 2014. 
22. Zhang K, Zhu S, Liu Y, Dong X, Shi Z, Zhang A, Liu C, Chen L, Wei J, Pu P, et al: ICAT inhibits glioblastoma cell proliferation by suppressing Wnt/B-catenin activity. Cancer Lett 357: 404-411, 2015.

23. Tan Z, Zheng H, Liu X, Zhang W, Zhu J, Wu G, Cao L, Song J, Wu S, Song L and Li J: MicroRNA-1229 overexpression promotes cell proliferation and tumorigenicity and activates Wnt/ $\beta$-catenin signaling in breast cancer. Oncotarget 7: 24076-24087, 2016.

24. Louis DN, Ohgaki H, Wiestler OD, Cavenee WK, Burger PC, Jouvet A, Scheithauer BW and Kleihues P: The 2007 WHO classification of tumours of the central nervous system. Acta Neuropathol 114: 97-109, 2007.

25. Livak KJ and Schmittgen TD: Analysis of relative gene expression data using real-time quantitative PCR and the 2(-Delta Delta C(T)) method. Methods 25: 402-408, 2001.

26. Betel D, Wilson M, Gabow A, Marks DS and Sander C: The microRNA.org resource: Targets and expression. Nucleic Acids Res 36: D149-D153, 2008.

27. Huang DW, Sherman BT and Lempicki RA: Systematic and integrative analysis of large gene lists using DAVID Bioinformatics Resources. Nat Protoc 4: 44-57, 2009.

28. Huang da W, Sherman BT and Lempicki RA: Bioinformatics enrichment tools: Paths toward the comprehensive functional analysis of large gene lists. Nucleic Acids Res 37: 1-13, 2009.

29. Ramis G, Villalonga-Planells R, Serra-Sitjar M, Brell M, Fernández de Mattos S and Villalonga P: The tumor suppressor FOXO3a mediates the response to EGFR inhibition in glioblastoma cells. Cell Oncol (Dordr) 42: 521-536, 2019.

30. Peng Y, He X, Chen H, Duan H, Shao B, Yang F, Li H, Yang P, Zeng Y, Zheng J, et al: Inhibition of microRNA-299-5p sensitizes glioblastoma cells to temozolomide via the MAPK/ERK signaling pathway. Biosci Rep 38: BSR20181051, 2018.

31. Zhang W, Shen C, Li C, Yang G, Liu H, Chen X, Zhu D, Zou H, Zhen Y, Zhang D and Zhao S: miR-577 inhibits glioblastoma tumor growth via the Wnt signaling pathway. Mol Carcinog 55: $575-585,2015$

32. Zeng A, Yin J, Li Y, Li R, Wang Z, Zhou X, Jin X, Shen F, Yan W and You Y: miR-129-5p targets Wnt5a to block $\mathrm{PKC} / \mathrm{ERK} / \mathrm{NF}-\mathrm{kappaB}$ and JNK pathways in glioblastoma. Cell Death Dis 9: 394, 2018

33. Zhang G, Chen L, Khan AA, Li B, Gu B, Lin F, Su X and Yan J: miRNA-124-3p/neuropilin-1(NRP-1) axis plays an important role in mediating glioblastoma growth and angiogenesis. Int J Cancer 143: 635-644, 2018.

34. Chen W, Kong KK, Xu XK, Chen C, Li H, Wang FY, Peng XF, Zhang Z, Li P, Li JL and Li FC: Downregulation of miR205 is associated with glioblastoma cell migration, invasion, and the epithelial-mesenchymal transition, by targeting ZEB1 via the Akt/mTOR signaling pathway. Int J Oncol 52: 485-495, 2018
35. Huang SW, Ali ND, Zhong L and Shi J: MicroRNAs as biomarkers for human glioblastoma: Progress and potential. Acta Pharmacol Sin 39: 1405-1513, 2018.

36. Yuan GQ, Wei NL, Mu LY, Wang XQ, Zhang YN, Zhou WN and Pan YW: A 4-miRNAs signature predicts survival in glioblastoma multiforme patients. Cancer Biomark 20: 443-452, 2017.

37. Lu D, Li Y, Liu QR, Wu Q, Zhang H, Xie P and Wang Q: Wls promotes the proliferation of breast cancer cells via Wnt signaling. Med Oncol 32: 140, 2015.

38. Jang GB, Hong IS, Kim RJ, Lee SY, Park SJ, Lee ES, Park JH, Yun CH, Chung JU, Lee KJ, et al: Wnt/ $\beta$-catenin small-molecule inhibitor CWP232228 preferentially inhibits the growth of breast cancer stem-like cells. Cancer Res 75: 1691-1702, 2015.

39. Gong A and Huang S: FoxM1 and Wnt $/ \beta$-catenin signaling in glioma stem cells. Cancer Res 72: 5658-5662, 2012.

40. Shin J, Shin Y, Oh SM, Yang H, Yu WJ, Lee JP, Huh SO, Lee SH, Suh YH, Chung S and Kim HS: MiR-29b controls fetal mouse neurogenesis by regulating ICAT-mediated $\mathrm{Wnt} / \beta$-catenin signaling. Cell Death Dis 5: e1473, 2014.

41. Liu J, Han P, Gong J, Wang Y, Chen B, Liao J and Tian D: Knockdown of KIAA1199 attenuates growth and metastasis of hepatocellular carcinoma. Cell Death Discov 4: 102, 2018.

42. Gan CP, Sam KK, Yee PS, Zainal NS, Lee BKB, Abdul Rahman ZA, Patel V, Tan AC, Zain RB and Cheong SC: IFITM3 knockdown reduces the expression of CCND1 and CDK4 and suppresses the growth of oral squamous cell carcinoma cells. Cell Oncol (Dordr) 42: 477-490, 2019.

43. Deng X, Liu Z, Liu X, Fu Q, Deng T, Lu J, Liu Y, Liang Z, Jiang Q, Cheng $C$ and Fang W: miR-296-3p negatively regulated by nicotine stimulates cytoplasmic translocation of c-Myc via MK2 to suppress cell growth, metastasis and chemotherapy resistance. Mol Ther 26: 1066-1081, 2018

44. Fu Q, Song X, Liu Z, Deng X, Luo R, Ge C, Li R, Li Z, Zhao M, Chen Y, et al: miRomics and proteomics reveal a miR-296-3p/PRKCA/FAK/Ras/c-Myc feedback loop modulated by $\mathrm{HDGF} / \mathrm{DDX} 5 / \beta$-catenin complex in lung adenocarcinoma. Clin Cancer Res 23: 6336-6350, 2017.

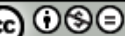

This work is licensed under a Creative Commons Attribution-NonCommercial-NoDerivatives 4.0 International (CC BY-NC-ND 4.0) License. 